\title{
Prevalence of overactive bladder symptoms and urinary incontinence in a tertiary care hospital in Egypt
}

\author{
Mustafa Bahloul, Ahmed M. Abbas*, Mervat A. Abo-Elhagag, \\ Elwani Elsnosy, Alaa-eldein A. Youssef
}

Department of Obstetrics and Gynecology, Faculty of Medicine, Assiut University, Egypt

Received: 15 April 2017

Accepted: 08 May 2017

*Correspondence:

Dr. Ahmed M. Abbas,

E-mail: bmr90@hotmail.com

Copyright: () the author(s), publisher and licensee Medip Academy. This is an open-access article distributed under the terms of the Creative Commons Attribution Non-Commercial License, which permits unrestricted non-commercial use, distribution, and reproduction in any medium, provided the original work is properly cited.

\begin{abstract}
Background: The current study aims to estimate the prevalence of Overactive bladder (OAB) and urinary incontinence (UI) among women attending Assiut Woman's Health Hospital. Additionally, to explore the impact of UI and OAB on The Quality of Life (QOL) of women.

Methods: A population-based survey included participants aged 18 years and older selected from Assiut Woman's Health Hospital and received The Bristol Female Lower Urinary Tract Symptoms Questionnaire (BFLUTSQ). OAB was defined in to two versions using the international continence society (ICS) definition of 2002 as either urgency sometimes or more alone (OAB1) or urgency sometimes or more with frequency more than eight times per day and /or nocturia once or more per night (OAB2). Incontinence and other LUTS were positive if answer scores $\geq 2$ to BFLUTSQ question for incontinence and other LUTS.

Results: The total prevalence of OAB was $39.0 \%$ (351 women). The prevalence of OAB dry and OAB wet was $26 \%$ (234 women) and 13\% (117 women), respectively, which suggested that $66.7 \%$ suffer from OAB dry and $33.3 \%$ suffer from $\mathrm{OAB}$ wet. The prevalence of dry OAB is significantly higher than wet $\mathrm{OAB}$. The overall prevalence of UI was $22.2 \%$ (201 women). The prevalence of stress UI, urge UI and mixed UI was 5.7\%, 5.1\% and $11.4 \%$, respectively.

Conclusions: OAB symptoms and UI are highly prevalent. Furthermore, both of them have severe effects on daily and sexual life as well as being related to psychological symptoms such as anxiety and depression.
\end{abstract}

Keywords: Lower urinary tract, Overactive bladder, Stress incontinence, Urinary incontinence

\section{INTRODUCTION}

The overactive bladder $(\mathrm{OAB})$ is a highly prevalent disorder that impacts the lives of millions of people worldwide. Despite its high prevalence, many sufferers do not seek medical attention and are not aware that OAB is treatable. ${ }^{1}$ Micturation disorders are responsible for increased morbidity throughout the world. This morbidity ranges from worrisome symptoms to life-threatening renal failure. Disturbances in voiding may sign neurological, metabolic, inflammatory, or infectious diseases. Voiding dysfunction may also arise from injury, outlet obstruction, structure changes in the bladder and urethra or loss of their supporting structures with aging. ${ }^{2}$

Research on urinary storage problems has focused on incontinence in women, but during last years, other urinary storage problems (urgency, frequency, and nocturia) has commanded attention worldwide. ${ }^{3}$ The prevalence of $\mathrm{OAB}$ is variable ranging from $3 \%$ to $43 \%$, depending on the population assessed and the definition used. ${ }^{4}$ The prevalence of OAB increase with age because of neurological and musculoskeletal effects, degenerative 
changes, and concurrent medical disorder such as diabetes. $^{5}$

$\mathrm{OAB}$ is defined by the international continence society (ICS) as a complex of symptom characterized by urinary urgency, with or without urge incontinence, usually with frequency and nocturia in the absence of urinary tract infection or other obvious pathology. ${ }^{6}$ Urgency is defined by The ICS as the complaint of sudden, compelling desire to pass urine which is difficult to defer. Urgency is considered the characteristic symptom of $\mathrm{OAB} .^{7}$

Urinary frequency (UF) can be reliably measured with a voiding diary. Traditionally, up to eight micturition episodes during waking hours has been considered normal. UF defined as daytime voiding frequencies of more than eight times, but this number is highly variable based upon hours of sleep, fluid intake, co-morbid medical conditions and other factors. ${ }^{8}$

Nocturiais referred to interruption of sleep one or more times because of the need to void. ${ }^{7}$ In one study, three or more episodes of nocturia constitutes moderate or major bother. ${ }^{9}$ Nocturia is a multifactorial symptom due to factors unrelated to $\mathrm{OAB}$ as excessive night-time urine production and sleep apnea. OAB greatly affects physical and social functioning, including work, sleep, and sexual relationships. ${ }^{10,11}$ Because of symptom frequency, OAB patients usually decrease water intake and limit daily activity to avoid the discomfort. ${ }^{12}$

There is some controversy about the classification and diagnosis of OAB. Some sources classify OAB in to "Wet" and "Dry" variants depending on whether it is an urgent need to urinate or if it includes incontinence. Wet variants are more common than dry variants. ${ }^{13}$

The prevalence of UI is relatively low early in life, has a peak around the time of menopause, and rise steadily between the age of 60 and 80 years. In Egypt the prevalence rate is higher when compared to other reports.El-Azabet al., 2007 reported that the prevalence rate of UI is $54.8 \%$ among Egyptian women. ${ }^{14}$ Stress, urge, and mixed urinary incontinence are most common types of urinary incontinence in women and have different risk factors. ${ }^{15}$

The current study aims to estimate the prevalence of $\mathrm{OAB}$ and UI among women attending a tertiary care hospital in Egypt. Also, to explore the impact of OAB and UI on the quality of life (QOL) of women.

\section{METHODS}

A population based survey, which was conducted in Assiut Women Health Hospital, Egypt between August 2015 and December 2016. The Assiut Medical Ethical Review Board approved the study. The study included 900women agreed to participate in the survey, aged 18 years and older randomly selected from the Gynecology clinic of the aforementioned hospital. Each woman received The Bristol female lower urinary tract symptoms questionnaire (BFLUTSQ) for completing it. Those who reported current pregnancy or having a urinary tract infection were excluded from the study.

The Bristol female lower urinary tract symptoms questionnaire (BFLUTSQ) is a validated questionnaire comprises of 34 questions related to incontinence, OABS (Four question items; day time frequency, nocturia, urgency, UUI) and other LUTS (Including intermittency, slow stream, straining, hesitancy, incomplete emptying, and inability to stop urinary flow) experienced during the last month as well as the impact of OABS and UI on sexual life and quality of life.

Participants whose responses were consistent with the 2002 ICS definitions of urgency (sometimes or more) alone or urgency sometimes or more with frequency more than eight times per day and/or nocturia once or more per night, with or without UUI were classified as having OAB. Incontinence (most common types are SUI, UUI and MUI) and other LUTS were positive if answer score $\geq$ 2 to BFLUTS Q question on UI and other LUTS. The questionnaire was translated to Arabic that resembles common speech in Egypt.

All basic criteria of the study participants as age, menopausal status, obstetric history, parity, educational level, surgical history (performed for incontinence or prolapse and history of hysterectomy), dietary habits, smoking and alcohol habits and any medical problems (Diabetes mellitus, Hypertension, Bronchial asthma) were collected by one of the study researchers.

\section{Statistical analysis}

All data were analyzed using SPSS software Chicago, IL, USA, version 21. Comparison between categorical variables in both groups was done by Chi-square test and continuous variables were compared using Student T-test. We considered $\mathrm{P}$ value $<0.05$ as a significant value.

\section{RESULTS}

Table 1 shows the demographic characteristics of the study participants. The mean age of the study participants was $41.45 \pm 15.92$ years.

Table 2 shows the prevalence of OAB symptoms and UI. The total prevalence of OAB was $39.0 \%$ (351). The prevalence of OAB dry and OAB wet was $26 \%$ (234) and $13 \%$ (117), respectively, which suggested that $66.7 \%$ suffer from OAB dry and $33.3 \%$ suffer from OAB wet. The prevalence of dry OAB is significantly higher than wet OAB. The overall prevalence of UI was $22.2 \%$ (201). The prevalence of SUI, UUI and MUI was 5.7\%, 5.1\% and $11.4 \%$, respectively. The prevalence of $\mathrm{OAB}$ with UUI, OAB with SUI and OAB with MUI was 9.7\%, $5.4 \%$ and $18.3 \%$, respectively. 
Table 3 shows the prevalence of other LUTS. Incomplete emptying of bladder was the most prevalent symptom in $36.8 \%$ of women, followed by inability to stop urinary flow in $28.4 \%$ of women. On the other hand, urinary retention was the least prevalent symptom that was present only in $1.6 \%$ of women.

Table 1: The demographic characteristics of the study participants.

\begin{tabular}{|l|l|}
\hline Characteristics & $\begin{array}{l}\text { Study participants } \\
(\mathbf{n}=900)\end{array}$ \\
\hline Age (years), mean \pm SD & $41.45 \pm 15.92$ \\
\hline Nulliparous & $148(16.5 \%)$ \\
\hline Previous CS & $272(30.2 \%)$ \\
\hline Postmenopausal & $343(38.1 \%)$ \\
\hline Educational level & $51(5.7 \%)$ \\
\hline Illiterate & $615(68.3 \%)$ \\
\hline Some high school & $184(20.4 \%)$ \\
\hline High school & $50(5.6 \%)$ \\
\hline College & $4(0.4 \%)$ \\
\hline Previous gynecological surgery \\
\hline Incontinence surgery & $32(3.6 \%)$ \\
\hline Prolapse surgery & $51(5.7 \%)$ \\
\hline Hysterectomy & \\
\hline Medical diseases & $62(6.9 \%)$ \\
\hline Diabetes mellitus & $21(2.3 \%)$ \\
\hline Hypertension & $53(5.9 \%)$ \\
\hline Bronchial asthma & $52(5.8 \%)$ \\
\hline Passive smoking & $747(83 \%)$ \\
\hline Caffeinated drinks & \\
\hline CS; cesarean section, SD; stand & \\
\hline
\end{tabular}

CS; cesarean section, SD; standard deviation. All data are presented as $\mathrm{n}(\%)$.

Table 2: The prevalence of overactive bladder symptoms and urinary incontinence.

\begin{tabular}{|l|l|}
\hline Symptoms & $\begin{array}{l}\text { Study } \\
\text { participants } \\
(\mathbf{n = 9 0 0 )}\end{array}$ \\
\hline Frequency, Score $\geq 3$ & $337(37.5 \%)$ \\
\hline Nocturia, Score $\geq 2$ & $319(35.4 \%)$ \\
\hline Urgency (Occasionally), Score $\geq 2$ & $364(40.4 \%)$ \\
\hline Urgency (sometimes), Score $\geq 3$ & $351(39.0 \%)$ \\
\hline Urge urinary incontinence (UUI) & $47(5.1 \%)$ \\
\hline Stress urinary incontinence (SUI) & $51(5.7 \%)$ \\
\hline Mixed urinary incontinence (MUI) & $103(11.4 \%)$ \\
\hline Urinary incontinence (UI) & $201(22.2 \%)$ \\
\hline Overactive bladder (OAB) & $351(39.0 \%)$ \\
\hline All data are presented as n (\%) & \\
\hline
\end{tabular}

Total prevalence of OAB was $39 \%$. Of these $50.1 \%$ (176 women) reported that their sexual life is spoilt by OABS and $29.9 \%$ (105 women) complained of dry vagina, $33.6 \%$ (118 women) had dyspareunia and 41.0\% (144 women) had coital incontinence. As regard quality of life, $16.8 \%$ of the women had to restrict their daily activities because of OABS and $37.0 \%$ reported their OABS affected their physical activities. Additionally, $54.4 \%$ of women said they affected their social life and $21.7 \%$ had to avoid places where toilet is far. There were also $50.1 \%$ of $\mathrm{OAB}$ patients have psychological symptoms such as anxiety and depression that make them would not by happy to spend the rest of their life with OABS.

Table 3: The prevalence of other lower urinary tract symptoms.

\begin{tabular}{|l|l|}
\hline Symptoms & $\begin{array}{l}\text { Study participants } \\
(\mathbf{n = 9 0 0 )}\end{array}$ \\
\hline Bladder pain & $112(12.4 \%)$ \\
\hline Unexplained urinary incontinence & $68(7.6 \%)$ \\
\hline Hesitancy & $221(24.6 \%)$ \\
\hline straining to start urination & $125(13.9 \%)$ \\
\hline Intermittency & $76(8.4 \%)$ \\
\hline Nocturnal enuresis & $46(5.1 \%)$ \\
\hline Abnormal Strength of stream & $154(17.1 \%)$ \\
\hline Urinary retention & $14(1.6 \%)$ \\
\hline Dysuria & $143(15.9 \%)$ \\
\hline Incomplete emptying & $331(36.8 \%)$ \\
\hline Inability to stop urinary flow & $256(28.4 \%)$ \\
\hline All data are presented as n $(\%)$ & \\
\hline
\end{tabular}

Total prevalence of UI was $22.2 \%$. Of them, $33.8 \%$ have reported avoiding sexual intimacy for fear of leaking of urine during sexual intercourse, $24.9 \%$ had coital incontinence, $13.9 \%$ complained of dry vagina and $16.4 \%$ had dyspareunia. In addition to $21.4 \%$ of the women had to restrict their daily activities and $34.8 \%$ had limited physical activity for fear of leaking urine. Also, $68.2 \%$ of women restrict social activity outside the home and $26.4 \%$ had to avoid going to work and other places for fear of leaking of urine.

\section{DISCUSSION}

Present study is population based study on the prevalence of $\mathrm{OAB}$ and UI in women aged $\geq 18$ years using the 2002 definition of ICS. Our results show that the weighted prevalence of OAB is $39 \%$ (13\% wet type and $26 \%$ dry type). This result is supported by many studies, where the prevalence of $\mathrm{OAB}$ is estimated to be in the range of $(3 \%-43 \%){ }^{4}$ The variation in prevalence is most likely due to definition dissimilarity of $\mathrm{OAB}$, design of questionnaires, study populations, and survey methods. In another study done in Egypt on 1652 women aged 20 years and older, the overall prevalence of OAB was $40 \%$ (26\% dry $\mathrm{OAB}$ and $14 \%$ with wet $\mathrm{OAB}$ ) which is consistent with the present study. ${ }^{14}$

Milson et al conducted a telephone survey of men and women in six European countries. ${ }^{4}$ The overall prevalence of $\mathrm{OAB}$ in individual aged $\geq 40$ years was $16.6 \%$ this study defined $\mathrm{OAB}$ as (comprising the symptom of increased day time frequency, urgency and urgency incontinency, occurring either single or in combination) which did not accord with the ICS 2002 definition. In our study, $40.4 \%$ of women have urgency 
and this was closer to the true prevalence of $\mathrm{OAB}$ based on the current definition.

National Overactive Bladder Evaluation (NOBLE) program interviewed 5204 individuals aged $\geq 18$ years by telephone in the united states. ${ }^{11}$ The prevalence of $\mathrm{OAB}$ was $16.9 \%$ in women in this study. The EPIC study evaluated the prevalence of all LUTS in five countries using the 2002 ICS definitions. This study reported that the prevalence of $\mathrm{OAB}$ in individuals aged $\geq 18$ years was $11.8 \% .^{16}$ In Asian courtiers, the prevalence of $\mathrm{OAB}$ in women aged $\geq 18$ years was reported to be $53.1 \%$ by use of a different definition of $\mathrm{OAB}$, which was the presence of frequency, urgency and urgency incontinency either single or in combination. ${ }^{17}$

Among individual with $\mathrm{OAB}, 66.7 \%$ suffer from $\mathrm{OAB}$ dry and $33.3 \%$ suffer from $\mathrm{OAB}$ wet in our study, which is consistent with the result of Zhang et $\mathrm{al}^{18}$, but contrary to the results of NOBLE study. ${ }^{11}$

In the present study, UI prevalence has been $22.2 \%$. This result is supported by many studies which estimate its prevalence to be in the range of $12-69 \%$, although estimates vary greatly in different countries and depend up on the age of the study group. ${ }^{19-22}$ In another study done in Egypt on 1652 women, the overall prevalence of UI was $54.8 \%$ (the prevalence of SUI, UUI and MUI was $14.8 \%, 15 \%$ and $25 \%$, respectively) which is higher than the present study. ${ }^{23}$

In our study, the prevalence of SUI, UUI and MUI was $5.7 \%, 5.1 \%$ and $11.4 \%$, respectively. Only few studies found mixed incontinence to be commonest type. ${ }^{23,24}$ Most of other studies in which stress insentience was commonest type..$^{25,26}$

In our study, the total prevalence of OAB was $39 \%$. Of these $50.1 \%$ (176) reported that their sexual life is spoilt by OABS, $16.8 \%$ (59) of the women had to restrict their daily activities, $37.0 \%$ (130) reported their OABS affected their physical activities and $54.4 \%$ (191) said they affected their social life. $21.7 \%$ (76) had to avoid places where toilet is far. $50.1 \%$ (176) of OAB suffers has psychological symptoms such as anxiety and depression that make them would not by happy to spend the rest of their life with OABS.

Total prevalence of UI was $22.2 \%$. Sixty-eight of the women with UI have reported avoiding sexual intimacy for fear of leaking of urine during sexual intercourse. Forty-three of them had to restrict their daily activities and 70 limited physical activity for fear of leaking urine. In another study done in Egypt on 1652 women, aged 20 years and older. Regarding the QOL, the most distressing issues for women with $\mathrm{OAB}$ and UI were their inability to pray (92\% and $90 \%$, respectively), other aspect of QOL are affected also. ${ }^{23}$
When compared with other studies, participants with $\mathrm{OAB}$ in our study reported significantly less work productivity, decrease sexual activity and anxiety symptoms, which is consistent with previous research on the impact of $\mathrm{OAB}$ on quality of life. ${ }^{27}$ In population based prevalence survey, OAB was associated with clinical and statistically higher depression scores, poorer sleep quality and lower levels of overall health - related quality of life. ${ }^{11}$

A recent study, which used the HADS (Hospital anxiety and Depression scale) to investigate the impact of $\mathrm{OAB}$ on mental health, reported that rates of clinically elevated anxiety and depression were markedly higher, particularly among people with bothersome OAB. Irwin et $\mathrm{al}^{28}$ also found that $\mathrm{OAB}$ was related to greater feelings of depression and stress, as well as compromising patients' working live. Indeed, the effect of $\mathrm{OAB}$ symptoms on HRQOL was the same as the effect of UI.

\section{CONCLUSION}

In conclusion, this population-based survey confirmed that $\mathrm{OAB}$ symptoms are highly prevalent. Furthermore, $\mathrm{OAB}$ has severe effects on daily and sexual life as well as being related to psychological symptoms such as anxiety and depression. Also, urinary incontinence is a very distressing problem. With the help of simple questionnaire, burden of the disease can be estimated. Knowing about prevalence and risk factors of OAB \& UI is very important, so that necessary steps in their prevention and treatment can be taken.

Funding: No funding sources Conflict of interest: None declared

Ethical approval: The study was approved by the Institutional Ethics Committee

\section{REFERENCES}

1. Abrams P, Cardozo L, Fall M, Griffiths D, Rosier P, Ulmsten U, et al. The standardization of terminology of lower urinary tract function: report from the Standardization Sub-committee of the International Continence Society. Am J Obstet Gynecol. 2002;1(187):116-26.

2. Steers WD, Barrett DM, Wein AJ. Voiding Dysfunction: Diagnosis, Classification, and Management. In: Gillenwater JY, Grayhack JT, eds. Adult and Pediatric Urology. vol. 3. Anne S. Patterson, 26B; 1996:1220-1310.

3. Ouslander JG. Management of Overactive Bladder. N Engl J Med. 2004;350(8):786-99.

4. Milson I, Abrams P, Cardozo L, Roberts RG, Thuroff J,Wein AG, et al. How wide spead are symptoms of an overactive bladder and how managed? A population-based prevalence study. BJU Int. 2001; 87:760-6.

5. Coyne K, Revicki D, Hunt T, Corey R, Stewart W, Bentkover $\mathrm{J}$, et al. Psychometric validation of 
overactive bladder symptom and health-related quality of life questionnaire: the OAB-q. Qual life Res. 2002;11:563-74.

6. Abrams P, Cardozo L, Fall M, Griffiths D, Rosier P, Ulmsten, $U$ et al: The standardization of terminology in lower urinary tract function: Report from the standardization sub-committee of the International Continence Society. Urology. 2003;61:37-49.

7. Haylen BT, De Ridder D, Freeman RM, Swift SE, Berghmans B, Lee $\mathrm{J}$, et al. An International Urogynecological Association (IUGA)/International Continence Society (ICS) joint report on the terminology for female pelvic floor dysfunction. Int Urogynecol J. 2010;21(1):5-26.

8. Fitzgerald MP, Brubaker L. Variability of 24-hour voiding diary variables among asymptomatic women. J Urol. 2003;169:207.

9. Tikkinen KA, Johnson TM, Tammela TL, Sintonen $\mathrm{H}$, Haukka J, Huhtala H, et al. Nocturia frequency, bother, and quality of life: how often is too often? A population-based study in Finland. Eur urol. 2010;57(3):488-98.

10. Coyne KS, Payne C, Bhattacharyya SK, Revicki DA, Thompson C, Corey R, et al. The impact of urinary urgency and frequency on health-related quality of life in overactive bladder: results from a national community survey.Value in health .2004;7(4):45563.

11. Stewart W, Van Rooyen J, Cundiff G, Abrams P, Herzog A, Corey R, et al. Prevalence and burden of overactive bladder in the United States. World J urol. 2003;20(6):327-36.

12. Kelleher CJ, Resse PR, Pleil AM, Okano GJ. Healthrelated quality of life of patients receiving extendedrelease tolterodin for overactive bladder. Am J Manag Care. 2002;8(19):S608-15.

13. Domchowski RR, Newman DK. Impact of Overactive Bladder on Women In the United States: results of a national survey. Curr Med Res Opin. 2007;23(1):65-76.

14. El-Azab AS, Moeen AM. The satisfaction of patients with refractory idiopathic overactive bladder with onabotulinumtoxinA and augmentation cystoplasty. Arab J Urol. 2013;11(4):344-9.

15. Altaweel W, Alharbim M. Urinary incontinence. Prevalence, risk factors, and impact on health related quality of life in Saudi women. Neurourol Urodyn. 2012;13:642-5.

16. Irwin DE, Milsom I, Kopp Z, et al. Impact of overactive bladder symptoms on employment, social interactions and emotional well- being in six European Countries. BJU Int. 2006;97:96-100.

17. Lapitan MC, Chye PL. Asia - Pacific Continence Advisory Board. The epidemiology of overactive bladder among females in Asia: a questionnaire survey- Int Urogynecol JP Pelvic Floor Dysfunct. 2001;12:229-31.

18. Zhang W, Song Y, He X, Huang H, Xu B, Song J. Prevalence and risk factors of overactive bladder syndrome in Fuzhou Chinese women. Neurourology and urodynamics. 2006;25(7):717-21.

19. Botlero F, Urquhart DM, Davis SR, Bell RJ. Prevalence and incidence of UI in women review of the literature and investigation of methodological issues. Int Urol. 2008;15:230-4.

20. Lasserre A , Pelat C, Gueroult V, Hanslik T, Chartier-Kastler E, Blancho T, et al. UI in French women: prevalence, risk factors, and impact on quality of life. Eur Urol. 2009;56:177-83.

21. Correia S, Dinis P, Rolo F, Lunet N. Prevalence, treatment and known risk factors of urinary incontinence and overactive bladder in the noninstitutionalized Portugues population. Int Urogynecol JP Pelvic Floor Dysfunct. 2009;20:14819.

22. Cerruto MA, D' Elia C, Aloisi A, Fabrello M, Artibani W. Prevalence, incidence and obstetric factors impact on female urinary incontinence in Europe: a systemic review Urol Int. 2013;90:1-9.

23. El-Azab AS, Mohammed EM, Sabra HI. The prevalence and risk factors of urinary incontinence and its influence on the quality of life among Egyptian women.Neurourolurodyn. 2007;26:783-8.

24. Peyrat L, Haillot O, Bruyere F, Boutin JM, Bertrand $\mathrm{P}$, Lanson Y. Prevalence and risk factors of urinary incontinencein young and middle aged women. BJU Int. 2002;89:61-6.

25. kinchen KS, Burgio K, Diokno AC, Fultz NH, Bump R, Obenchain R. Factor associated women's decisions to seek treatment for urinary incontinence. J Women Health (larchmt) 2003;12:687-98.

26. AL-Badr A, Brasha H, Al- Raddadi R, Noorwali F, Ross S. Prevalenceof urinary incontinence among Saudiwomen.Int J Gynaecol Obstet. 2012;117:160-3.

27. Rosen RC, Giuliano F, Carson CC. Sexual dysfunction and lower urinary tract symptoms (LUTS). Eur Urol. 2005;47:824-37.

28. Irwin P, Somov P, Ekwueme K. Patient reported outcomes of abobotulinum toxin A injection treatment for idiopathic detrusor overactivity: Apragmatic approach to management in secondary care. J Clin Urol. 2013;6:1.

Cite this article as: Bahloul M, Abbas AM, AboElhagag MA, Elsnosy E, Youssef AA. Prevalence of Overactive bladder symptoms and urinary incontinence in a tertiary care hospital in Egypt. Int $\mathbf{J}$ Reprod Contracept Obstet Gynecol 2017;6:2132-6. 